\title{
DIFFUSE OLIGOSYMPTOMATIC CAROLI'S DISEASE: CASE REPORT
}

\author{
LEMFADLI $\mathrm{Y}^{1}$, BOUCHRIT $\mathrm{S}^{1}$, AIT ERRAMI A ${ }^{1}$, OUBAHA $\mathrm{S}^{2}$, SAMLANI $\mathrm{Z}^{1}$, KRATI K ${ }^{1}$
}

\begin{abstract}
This article describes a case of Caroli's disease in a 53-year-old female patient who complained nonspecific abdominal pain without cholestasis or cholangitis. Ultrasound and hepatic magnetic resonance imaging showed segmental saccular dilations connected to intrahepatic bile ducts without hepatic fibrosis. This clinical case shows the possibility of having oligosymptomatic forms in the diffuse forms of Caroli disease, therefore the interest to consider this diagnosis in case of non-specific abdominal signs and to request a hepatic ultrasound.
\end{abstract}

Keywords: Caroli disease, Caroli syndrome, congenital bile duct dilatation.

Received: 16 April 2020

Accepted: 12 June 2020

DOI: https://doi.org/10.3329/bjm.v31i2.48540

\section{Introduction}

Caroli's disease (CD) is a rare congenital disease, first described in 1958 by Jacques Caroli. ${ }^{1}$ It is part of the spectrum of fibropolycystic liver pathologies. It is characterized by congenital non-obstructive dilation of the intrahepatic bile ducts. It can be localized or diffuse. Caroli syndrome is defined as its association with congenital hepatic fibrosis. ${ }^{2}$ It is most often revealed by recurrent episodes of cholangitis. ${ }^{3}$

This article describes the case of CD in a 53-year-old female patient with cystic formations distributed throughout the hepatic parenchyma, fortuitously diagnosed in adulthood, during the etiological investigation of non-specific abdominal pain.

\section{Case report}

A 53-year-old female patient was seen in consultation. She complained of abdominal pain, which had started a year ago. The intensity of the pain was mild to moderate, intermittent, recurrent, located in the upper right quadrant and relieved by taking first-level pain relievers. The patient also reported urinary burns, but no fever or chills. She did not report jaundice, pruritus, vomiting, or weight loss.

The patient had no history of personal or family hepatopathy. She was taking no treatment and no toxic habits.

The clinical examination, in particular the abdominal, respiratory and cardiovascular examination, did not show any abnormalities. There was no jaundice or fever. The abdominal examination did not show hepatomegaly or signs of hepatocellular insufficiency or portal hypertension.
Hematological and biochemical examinations were normal (Table 1). There was no cholestasis or cytolysis. The levels of alpha-foeto-protein and carcinoembryonic antigen were normal. The cytobacteriological examination of the urine was sterile.

Table-I

Hematological and biochemical parameters

\begin{tabular}{|c|c|}
\hline Parameters & Results \\
\hline Hemoglobin & $12.3(\mathrm{~g} / \mathrm{dL})$ \\
\hline Hematocrit & $37,3(\%)$ \\
\hline Leukocytes & $4950(/ \mathrm{mm} 3)$ \\
\hline Platelets & $191(/ \mathrm{mm} 3)$ \\
\hline Prothrombin activity & $100(\%)$ \\
\hline C-reactive protein & 1,6 (mg/L) \\
\hline AST & 21 (UI/L) \\
\hline ALT & $12(\mathrm{UI} / \mathrm{L})$ \\
\hline GGT & $21(\mathrm{U} / \mathrm{L})$ \\
\hline Alkaline phosphatase & 67 (U/L) \\
\hline Total bilirubin & $6(\mathrm{mg} / \mathrm{L})$ \\
\hline Albumin & $46.8(\mathrm{~g} / \mathrm{L})$ \\
\hline$\alpha$-Fetoprotein & $1.6(\mathrm{ng} / \mathrm{mL})$ \\
\hline CEA & $3(\mathrm{ng} / \mathrm{mL})$ \\
\hline LDH & 349 (U/L) \\
\hline Urea & $0.35(\mathrm{~g} / \mathrm{L})$ \\
\hline Creatinine & $6(\mathrm{mg} / \mathrm{L})$ \\
\hline
\end{tabular}

AST: aspartate aminotransferase

ALT: alanine aminotransferase

GGT : $\alpha$-glutamyl transferase

CEA : carcinoembryonic antigen

LDH : lactate dehydrogenase

1. Gastroenterology Department, Mohammed VI University Hospital, Marrakech

2. Physiology Department, Faculty of Medicine and Pharmacy at Cadi Ayyad University, Marrakech

Address of Correspondence: Dr. Lemfadli Y, Gastroenterology Department, Mohammed VI University Hospital, Marrakech

Bangladesh J Medicine 2020; 31 : 107-110 

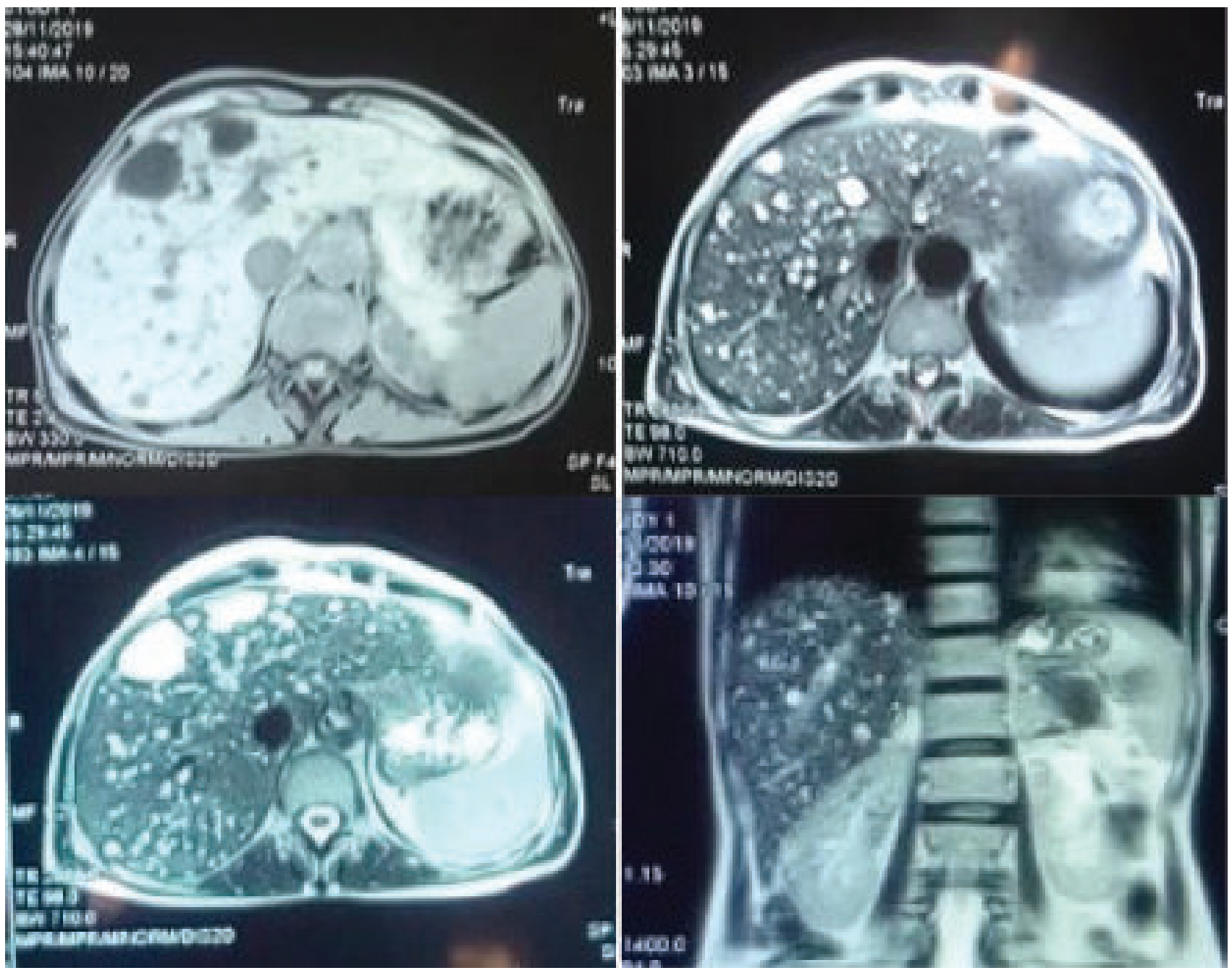

Figure 1: Magnetic resonance imaging showing ectasias of the intrahepatic bile ducts and communication with the bile branches

Abdominal ultrasound showed cystic formations throughout the hepatic parenchyma which seem to communicate with the intrahepatic bile ducts. There is no calculus or liver nodule. Magnetic resonance imaging (MRI) (Figure 1) confirmed the diagnosis of CD. The liver was of normal size, with regular contours with the presence of multiple cystic formations in hyposignal $\mathrm{T} 1$ and hypersignal $\mathrm{T} 2$, with thin walls. These cystic lesions are connected to and communicate with the intrahepatic bile ducts.

Liver biopsy was not performed because the procedure would bring more risks than benefits. Currently, the patient continues her regular clinical follow-up in consultation. She has no major clinical manifestations that affect her daily life. The prognosis for her illness is favorable at the moment, since the patient has no complications including no cholangitis and no signs of portal hypertension or malignancy.

\section{Discussion}

Caroli's disease is a rare autosomal recessive inherited congenital disease. Rare cases of autosomal dominant transmission have been reported. ${ }^{4}$ Its incidence is estimated at 1 per million of the population [5]. It is associated with incomplete and defective remodeling of the embryonic ductal plate.$^{6,7}$ It is usually diagnosed in childhood or adolescence ${ }^{4}$, but can be diagnosed in adulthood. ${ }^{8-10}$ No sex predominance has been reported. ${ }^{11}$

The clinical symptomatology of $\mathrm{CD}$ is not specific. Patients may be asymptomatic or have symptoms such as jaundice, right upper quadrant pain or fever. ${ }^{12}$ Intrahepatic ductal ectasia predisposes to the stagnation of bile, which can lead to the formation of stones and predisposes to repeated cholangitis which can be complicated by serious infections such as liver abscess or septicemia. ${ }^{13,14}$ Chronic inflammation due 
to gallstones in the intrahepatic ducts can lead to secondary biliary cirrhosis with its complications such as portal hypertension. ${ }^{14}$

Liver function tests in CD may be normal or there may be reversible increases during episodes of cholangitis [15]. The level of alkaline phosphatase and direct bilirubin may be increased. The level of transaminases can be normal as it can be high and reflect a progressive hepatic fibrosis in case of Caroli syndrome. ${ }^{14}$

The final diagnosis is confirmed by histopathology, but current non-invasive imaging tools, including ultrasound (US), computed tomography (CT) and magnetic resonance imaging (MRI) are considered to be the first-line diagnostic modalities. ${ }^{16}$ The ultrasound shows saccular or spindle-shaped cystic dilations predominant around the hepatic hilum without any underlying obstacle and which communicate with the rest of the biliary tree. It is a very good technique for visualizing intrahepatic lithiasis. Doppler ultrasound or multi-slice CT also enable visualization of the pathognomonic "dot sign", which represents a portal or arterial branch at the periphery of or within a pseudoseptation running through a cyst. ${ }^{17}$ Magnetic resonance imaging (MRI) is a non-invasive technique that currently presents the most specific tool for diagnosing $\mathrm{CD}$. It demonstrates cystic structures of variable size which communicate freely with the biliary tree as well as the "dot sign" and intrahepatic stones. ${ }^{18}$ Caroli syndrome differs from $\mathrm{CD}$ by the presence of smaller cystic structures $(<2 \mathrm{~cm})$ connected to the bile ducts with periportal fibrosis. ${ }^{19}$

The management of CD depends on the symptomatology of the patient and the extent of biliary abnormalities. ${ }^{10}$ Cholangitis can be managed with antibiotics. In the case of cholestasis with intrahepatic lithiasis, the prescription of ursodeoxycholic acid is an option. ${ }^{17,20}$ Surgical resection by lobectomy is recommended in case of localized disease in a lobe. ${ }^{21}$ It reduces the risk of degeneration into cholangiocarcinoma which to be as high as 100-fold greater in patients with $\mathrm{CD}$ than in the general population. ${ }^{22}$ However, in cases of diffuse disease and in case of suspected malignant transformation, liver transplantation remains the treatment of choice. ${ }^{23}$ In case of biliary obstruction, an endoscopic sphincterotomy, radiological or surgical drainage may be applied. ${ }^{15}$

\section{Conclusion}

Caroli disease poses a double diagnostic and therapeutic problem. The rarity of the disease, the absence of specific clinical signs and the frequent association with gallstones make diagnosis difficult.
Treatment of diffuse forms is problematic and requires liver transplantation given the risk of septic complications, secondary biliary cirrhosis and degeneration.

\section{References}

1. Pimentel F. Enfermedad de Caroli. Rev Chil Cir 2004;56:426-433.

2. Gupta AK, Gupta A, Bhardwaj VK, Chansoria M. Caroli's disease. Indian J Pediatr 2006;73:233-235. https:// doi.org/10.1007/BF02825490 PMid:16567920

3. Menon S, Holt A. Large-duct cholangiopathies: aetiology, diagnosis and treatment. Frontline Gastroenterol. 2019;10(3):284 291. https://doi.org/ 10.1136/flgastro-2018-101098 PMid:31288256 PMCid:PMC6583582

4. R. Torra, C. Badenas, A. Darnell, C. Br 'u, A. Escorsell, and X. Estivill, "Autosomal dominant polycystic kidney disease with anticipation and Caroli's disease associated with a PKD1 mutation rapid communication," Kidney International, vol.52, no. 1, pp. 33-38, 1997. https://doi.org/10.1038/ki.1997.300 PMid:9211343

5. Bakoyiannis A, Delis S, Triantopoulou C, Dervenis C: Rare cystic liver lesions: a diagnostic and managing challenge. World J Gastroenterol 2013; 19(43):76037619. https:// doi.org/10.3748/wjg.v19.i43.7603 PMid:24282350 PMCid:PMC3837259

6. Khalefa, A.A., Alrasheed, M. \& Saeedan, M.B. Central dot sign. Abdom Radiol 41, 2289-2290 (2016). https:/ /doi.org/10.1007/s00261-016-0836-2 PMid: 27392743

7. Sato Y, Harada K, Kizawa K, Sanzen T, Furubo S, Yasoshima M et al. (2005) Activation of the MEK5/ERK5 cascade is responsible for biliary dysgenesis in a rat model of Caroli's disease. Am J Pathol 166:49-60. https://doi.org/10.1016/S0002-9440(10)62231-6

8. Acioli, Maíra Lima et al. "Diffuse Caroli's disease with atypical presentation: a case report." Annals of gastroenterology vol. 27,1 (2014): 79-81.

9. Sarker, I., Bhuiyan, A. M., \& Sarker, M. Z. (2016). A middle aged man with Caroli's disease: A case report. Bangabandhu Sheikh Mujib Medical University Journal, 9(1), 50-52. https://doi.org/10.3329/ bsmmuj.v9i1.28945

10. Wang ZX, Li YG, Wang RL, Li YW, Li ZY, Wang LF, Yang HY, Zhu Y, Wang Y, Bai YF et al: Clinical classification of Caroli's disease: an analysis of 30 patients. HPB (Oxford) 2015; 17(3):278-283. https://doi.org/ 10.1111/hpb.12330. PMid:25327281 PMCid:PMC 4333791

11. Madjov R, Chervenkov P, Madjova V, Balev B. (2005) Caroli's disease. Report of 5 cases and review of literature. Hepatogastroenterology 52:606-609. 
12. Huang, Xiao-ming. "Factors contributing to diagnostic delay of Caroli syndrome: a single-center, retrospective study." (2020).

13. Cabral Correia P, Morgado B (September 20, 2017) Caroli's Disease as a Cause of Chronic Epigastric Abdominal Pain: Two Case Reports and a Brief Review of the Literature. Cureus 9(9): e1701. https://doi.org/ 10.7759/cureus.1701 PMid:29159008 PMCid:PMC 5690396

14. Yonem, Ozlem, and Yusuf Bayraktar. "Clinical characteristics of Caroli's disease." World journal of gastroenterology vol. 13,13 (2007): 1930-3. https:// doi.org/10.3748/wjg.v13.i13.1930 PMid:17461492 PMCid:PMC4146968

15. Yadav, Padmini et al. "Caroli's disease: a diagnostic challenge." International Surgery Journal 5 (2018): 3750. https://doi.org/10.18203/23492902.isj20184657

16. Cannella R, Giambelluca D, Diamarco M, Caruana G, Cutaia G, Midiri M, Salvaggio G: Congenital Cystic Lesions of the Bile Ducts: Imaging-Based Diagnosis. Curr Probl Diagn Radiol 2019. https://doi.org/ 10.1067/j.cpradiol.2019.04.005 PMid:31027922

17. Caroli's disease: current knowledge of its biliary pathogenesis obtained from an orthologous rat model Int J Hepatol, 2012 (2012), pp. 1-10. https://doi.org/ 10.1155/2012/107945 PMid:22007315 PMCid: PMC3168917

18. Guy F, Cognet F, Dranssart M, Cercueil JP, Conciatori L, Krause D. Caroli's disease: magnetic resonance imaging features. Eur Radiol 2002;12:2730-2736. https://doi.org/10.1007/s00330-002-1471-6 PMid: 12386765

19. Strazzabosco M, Fabris L, Spirli C. Pathophysiology of cholangiopathies. J Clin Gastroenterol 2005;39:S90S102. https://doi.org/10.1097/01.mcg.0000155549. 29643.ad PMid:15758666

20. Ananthakrishnan AN, Saeian K: Caroli's disease: identification and treatment strategy . Curr Gastroenterol Rep. 2007, 9:151-155. 10.1007/s11894007-0010-7 https://doi.org/10.1007/s11894-0070010-7 PMid:17418061

21. Chen CB, Hu WD, Zhao WW, Gu YY, Hou HW, Pan Z. Laparoscopic hepatectomy for the treatment of Caroli's disease: a case report. Ann Surg Treat Res. 2018 Mar;94(3):162-165. https://doi.org/10.4174/ astr.2018.94.3.162 PMid:29520352 PMCid:PMC5 842090

22. Jang $\mathrm{MH}$, Lee $\mathrm{YJ}$, Kim $\mathrm{H}$. Intrahepatic cholangiocarcinoma arising in Caroli's disease. Clin Mol Hepatol 2014;20:402-405. https://doi.org/10.3350/ cmh.2014.20.4.402 PMid:25548748 PMCid:PMC 4278073

23. DeKerckhove L., De, Meyer M., Verbaandert, C., Mourad, M., Sokal, E., Goffette, P., Geubel, A., Karam, V., Adam, R., and Lerut, J. The place of liver transplantation in Caroli's disease and syndrome. Transpl.Int. 2006; 19: 381-388. https://doi.org/ 10.1111/j.1432-2277.2006.00292.x PMid:16623873. 